\title{
SURFACE MODIFICATIONS AND PROPERTIES FOR CARYOTA URENS CELLULOSE FIBERS REINFORCED POLYMER COMPOSITES
}

\author{
CH. VENKATA PRASAD ${ }^{1}$, Dr. K L. NARAYANA ${ }^{2} \&$ Dr. V V. SUBBA RAO ${ }^{3}$ \\ ${ }^{1}$ Assistant Professor, Velagapudi Ramakrishna Siddhartha Engineering College, Vijayawada, India \\ ${ }^{2}$ Professor \& Dean, R\&D, K L University, Vaddeswaram, Guntur, India \\ ${ }^{3}$ Professor \& Principal, Mechanical Department, UCEN Narasaraopeta, JNTUK, India
}

\begin{abstract}
The aim of this paper is to characterise and improve the mechanical properties by surface modifications of caryotaurens natural fiber. The fiber was obtained by retting treatment. Advantages of natural fibers are of low cost, low density, and biodegradability. Natural fibers in composites have the fundamental downsides are high moisture absorption and low compatibility between fibers and matrix. Therefore to modify the surface properties, chemical treatments are used. The fiber chemical treatment was targeted at enhancing the surface strength and the adhesion between the surface of the fiber and the polymer matrix. The different chemical treatments such as alkalization, benzoylation on natural fiber such as caryotaurens were done, so that mechanical properties such as tensile modulus, tensile strength, impact strength, flexural strength, and hardness can be improved and compared with and without treatment of the fiber at $20 \%, 30 \%$ and $40 \%$ of volume fraction in the composite. Mechanical properties are enhanced and water absorption of composites is reduced.

Morphological investigation was performed using scanning electron microscopy (SEM) analysis for the treated and untreated fibers to study the effect of chemical treatment. It was observed that tensile properties, impact strength, flexural strength and hardness are improved by both the treatments but alkaline treatment gives the higher strength value than benzyl chloride treatment.
\end{abstract}

KEYWORDS: CaryotaUrens, Mechanical Properties, Alkaline Treatment \& Benzoylation

Received: May 20, 2020; Accepted: Jun 10, 2020; Published: Jun 29, 2020; Paper Id.: IJMPERDJUN2020126

\section{INTRODUCTION}

Cellulose fiber reinforced polymer matrix has turned into a striking exploration subject for the scientist over the previous decades. This sort of materials combinations have been examined for locate an appropriate supplanting of manufactured fibers with cellulose fibers [1,2].Natural fiber composites draw in light of a legitimate concern for scientists because of their particular properties and no unsafe consequences on environment. Less cost generation, low vitality utilization and tremendous accessibility, eco-friendly, and extraordinary specific strength, and less thickness are the principle aims for the usage of cellulose fibers as an element of the regular fiber composites [3]. Various sorts of natural fibers are accessible in the environment, for example, hemp, sisal, flax, jute, okra, ferula, coir are utilized in the polymer matrix reinforcement. [4-7]. Most automotive industries are supplanting synthetic fibers such as carbon and glass by cellulose fibers in to polymer matrix reinforcement. [8,9]. Cellulose fibers as fortification have a few disadvantages alongside number of advantages. At raised temperatures cellulose fibers are not steady. Cellulose fibers have hydrophilic nature that points of confinement them for humidity condition 
applications. [10]. It likewise leads dimension instability issue for reinforced fiber composite [11].

The reason for this is concealed in the natural fiber composition. The major elements of natural fiber are hemicellulose, cellulose, lignin and pectin. These are hydrophilic in nature because of the existence of a wealthy hydroxyl group that provides a powerful affinity to natural fibers towards humidity [12]. In nature, however matrix is predominantly water- repelled such as polypropylene, poly lactic acid and polyvinyl chloride [13]. Different chemical treatments are existing to enhance fiber matrix compatibility which could be used to improve the functionality of cellulose fiber composites [14].

Past investigators examined various kinds of cellulose fibers, for example, elephant grass, [15] jowar, [16] sansevieria,[17]Typhaangustifolia,[18] snake grass and vakka[20] from various sources, for example, leaf, stem, and fruit as a material for reinforcing in the development of cellulose polymer composites.In order to make cellulose fiber reinforced composites materials a decent alternative as a structural part, it is composites must have great interface holding between fiber part and network part for great flexural quality. From a decades ago (2000-2016) various chemical treatments utilized on cellulose fibers and their impact on mechanical characteristics of composites have been examined which can improve further potential outcomes of upgrades of cellulose fiber reinforced composites.

The primary objective of this research is to examine the influence of chemical treatment on a new natural resource , i.e., fish tail palm (caryotaurens) tree with lower manufacturing costs due to its abundance and ready accessibility, particu larly in India. Fish tail palm tree (Caryotaurens) is a fast-growing feather palm that makes a beautiful addition to the landscape. It belongs to the family of Arecaceae and is also called as toddy palm. It has a gray trunk that grows to about $15-20 \mathrm{~m}$ in height and is covered by regularly spaced leaf scar rings. The leaf shape resembles the tail of a fish, thereby earning the popular English name, fish tail palm. It is found more often in cool shady valleys from India to Burma and on the island country of Sri Lanka [20]. The fish tail palm tree stem is covered with single fibers in the form of mesh. Mechanical and thermophysical properties were done for this caryotaurens natural fiber reinforced polyester composites [21]. In this study, an effort was made to examine the effect of chemical treatment on mechanical properties such as tensile strength, tensile modulus, impact strength and hardness. These basic data are necessary for the design of the resultant composites.

\subsection{Introduction to CaryotaUrens}

Fish tail palm tree which is sustainable with less manufacturing cost due to its abundance and ready accessibility, primaril $\mathrm{y}$ in India. Fish tail palm tree is a fast-growing feather palm that makes a beautiful addition to the landscape. It belongs to the family of Arecaceae and is also called as toddy palm. It has a gray trunk that grows to about $15-20 \mathrm{~m}$ in height and is covered by regularly spaced leaf scar rings. The leaf shape resembles the tail of a fish, thereby earning the popular English name, fish tail palm. It is found more often in cool shady valleys from India to Burma and on the island country of Sri Lanka. The fish tail palm tree stem is enclosed with single fibers in the form of mesh. 


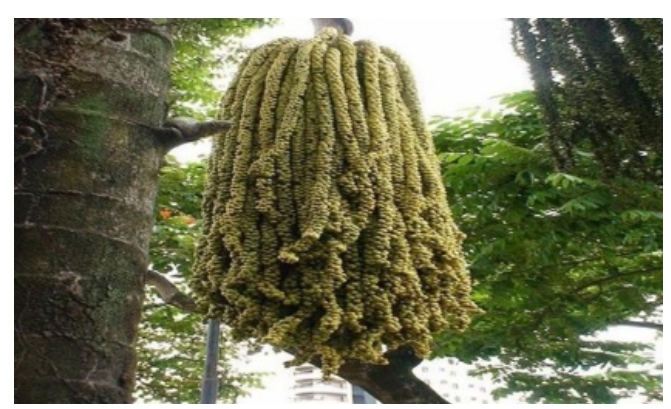

Figure 1: Fish tail palm Tree (caryotaurens)

\section{FIBER PREPARATION}

The crude fibers gathered from the plant were drenched with water about $20 \mathrm{~h}$ and afterward washed completely with detergent so as to wipe out residue and sand that may dirty the fibers on account of contact to the natural environment.The washed fibers were desiccated one week under the sun, trailed by $12 \mathrm{~h}$ oven drying at 700C, and after that slice to the favored length.

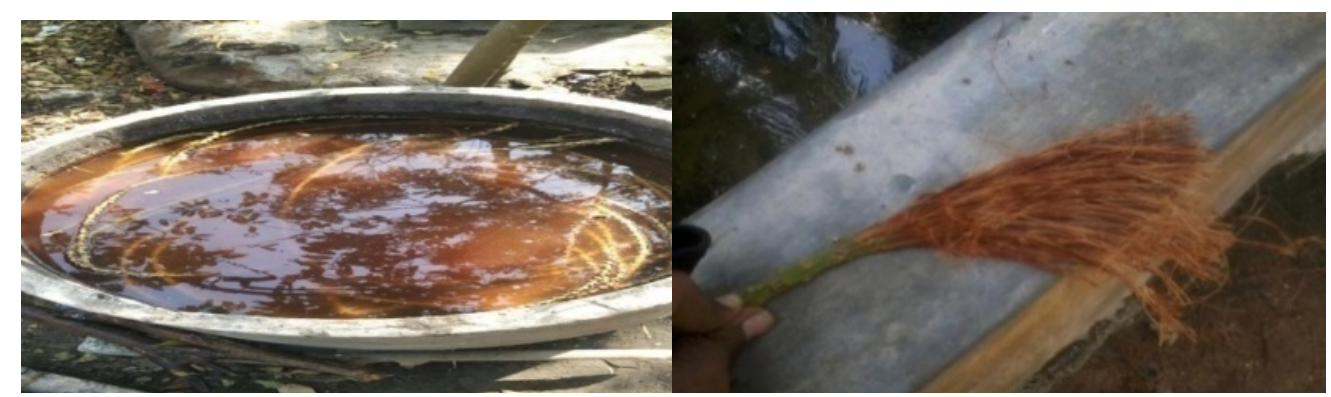

Figure 2(A): Retting Process of Fiber

Figure 2(B): Fiber after Retting Process

\section{CHEMICAL TREATMENT OF FIBER}

\subsection{Alkaline Treatment}

Alkaline treatment (mercerization) is a standout amongst the most utilized chemical treatments of cellulose fibers reinforced polymers. The noteworthy alteration done by this treatment is the diversion of hydrogen holding in the system structure, accordingly expanding surface roughness. This treatment takes out a specific measure of lignin, wax and oils wrapper the outside surface of the fiber cell divider, depolymerizes cellulose and uncovered the crystallites of short length [22].The alkali reaction between caryotaurens fiber and sodium hydroxide $(\mathrm{NaOH})$ is:

Cellulose Fiber $-\mathrm{OH}+\mathrm{NaOH} \rightarrow$ Cellulose fiber $-\mathrm{O}-\mathrm{Na}+\mathrm{H}_{2} \mathrm{O}$

The caryotaurens fibers were soaked in a 5\% NAOH solution at room temperature maintain an alcohol ratio 15:1 for alkaline treatment and remaining immersion for 4 hours in this solution. The fibers were then washed several times with crisp water to prevent any NAOH adhering to the surface of the fiber, neutralized with diluted acetic acid and dried with distilled water. At last $\mathrm{pH}$ of 7 has been maintained. At room temperature the fibers were then dried for 48 hours pursued by oven drying for $6 \mathrm{hrs}$ at $100^{\circ} \mathrm{C}$.

\subsection{Benzoyl Treatment}

Benzoyl chloride is every now and again utilized in fiber treatment. It contains benzoyl $(\mathrm{C} 6 \mathrm{H} 5 \mathrm{C}=\mathrm{O})$ which is credited to the diminished hydrophilic nature of the treated fiber and improved cooperation with the hydrophobic polymermatrix 
composite.

Fiber benzoylation enhances fiber matrix adhesion and therefore considerably increases composite strength, decre ases water absorption and improves thermal stability.The reaction between the benzoyl chloride and cellulosic hydroxyl gr oup of fiber is as follows.

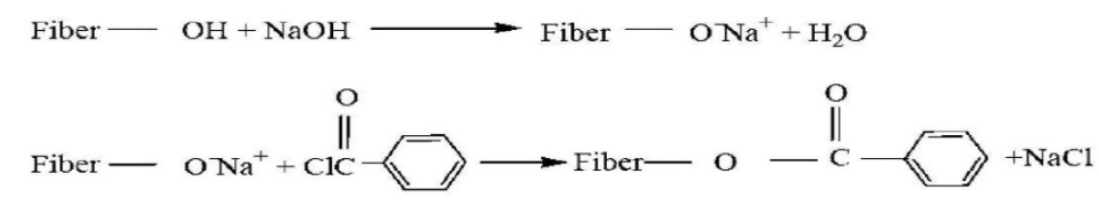

The pre-treated caryotaurensfibers were suspended in 10\% NAOH solution and agitated with Benzyl chloride. The mixture was kept 15 minutes, divided, totally splashed with water and parched between filter papers. Then ethanol was absorbed by the disengaged fibers for 1 hour to evacuate the benzyl chloridewas finally sprinkled with water and desiccated fibers in the oven for 24 hours at $80^{\circ} \mathrm{C}$.

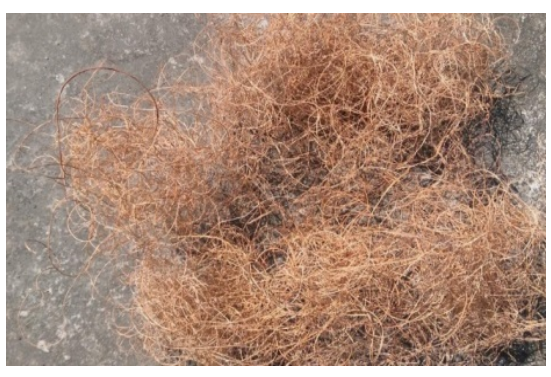

Figure 3(a): Un Treated Fiber

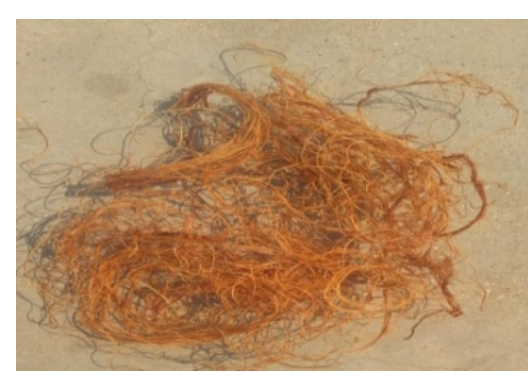

Figure3(b): Alkaline Treated Fiber

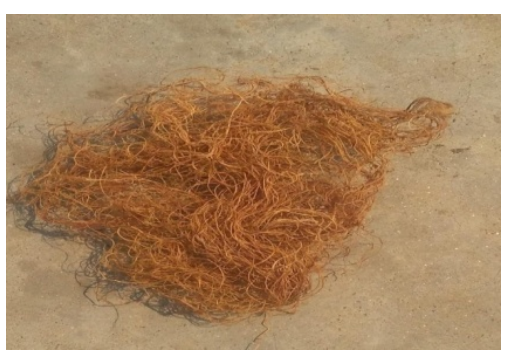

Figure 3(c): Benzyl Chloride Treated Fiber

\section{COMPOSITE FABRICATION}

A handcrafted wooden shape is intended for the production of the arbitrarily arranged crude caryotaurensfiber reinforced epoxy composite, Alkaline treated and (ACFREC) and benzyl chloride treated epoxy reinforced composite (BCFREC). Initial, a discharging plastic is propagating over the base of the mould. A semi-solid wax is applied in plastic sheet for simple evacuation of the composite.The fibers are cut into $20 \mathrm{~mm}$ length and conveyed consistently at the base of the shape. Primarily, epoxy and hardener mixer is prepared on a weight percentage of 10:1 to form a matrix. In order to avoid and remove air bubbles, the matrices evenly pressed over the fiber and pushed down with the iron roller. Eventually, it is loaded to remove surplus matrix and left restoring at ambient temperature for 24 hours.

\section{MECHANICAL TESTING OF COMPOSITE}

\subsection{Tensile Characteristics}

The typical test method ASTM D638-89 was used to measure the tensile properties of the composite. The Test specimens prepared according to the following dimensions are length $160 \mathrm{~mm}$, width $12.5 \mathrm{~mm}$ and thickness $3 \mathrm{~mm}$. Forevery fiber volume percentage, threeidentical test specimens are tested. An electronic tensometer is used to test the specimen with $2 \mathrm{~m} / \mathrm{min}$ is the crosshead speed.

\subsection{Flexural Testing of Composite}

Instron 1195 machine was used to conduct three-point bend tests according to ASTM D790 standard to measure the 
compositeflexural strength. The breaking energy and the toughness were calculated from the test results of the specimen. The maximum shear stress of the composite called instantaneous shear stress was measured from the above bending test.
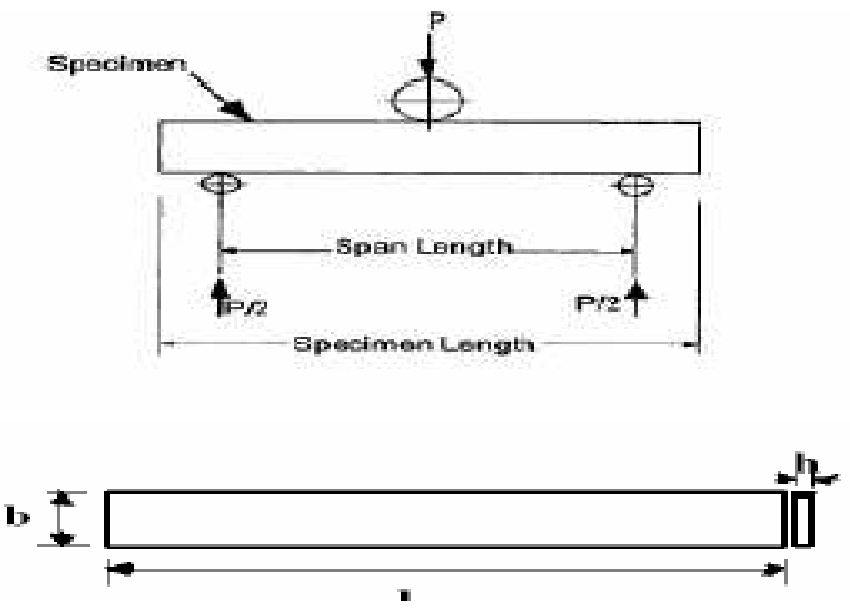

Figure 4: Flexural Testing Apparatus.

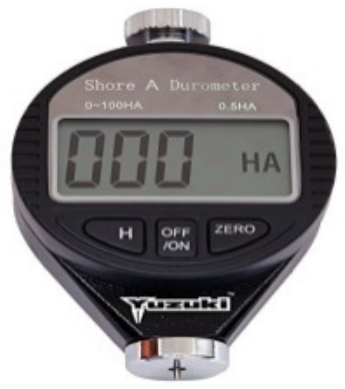

Figure 5: Durometer.

\subsection{Impact Testing of Composite}

The plastic Impact testing machine was used to calculate Impact strength of the composite. The notched specimen for Izod test was prepared according to ASTM D25688 slandered. The dimensions of the notched specimen were $12.7 \mathrm{~mm}$ depth and $10 \mathrm{~mm}$ width. The angle for $\mathrm{V}$ notch was $90^{\circ}$.

\subsection{Hardness Testing of Composite}

A durometer gage or durometer analyzer is expected to play out a durometer hardness test method. Durometer gadgets decide the surface hardness of a wide range of materials, including polymers and elastomers. Each durometer or hardness analyzer measures the profundity of a space in the material caused by a characterized power of a given geometric presser foot. The profundity of the space mirrors the hardness of the material. A general refinement is made amongst static and dynamic techniques. In customary static tests, the test compel is connected consistently with expanding extent, while in unique testing strategies, a prompt load is connected. As of plastic, metal, and elastic to foam and texture, diverse materials are measured utilizing divergent hardness scales, for example, ASTM D2240 sort An and sort D scales. For instance, delicate plastics are measured utilizing the sort A scale, while hard plastics are measured utilizing the sort D scale.

\subsection{SEM Analysis}

JEOL JSM6480LV scanning electron microscope (SEM)has been utilisedtostudythemorphology of treated and untreated fi ber surfaces. To convert fiber surfaces are conductive, they were gold coated prior the SEM investigation. It is well 
founded that natural fiber cellulose chains are firmly constrained by chemical components, lignin and hemicellulose, leading in multi-cellular fiber formation. The outside ofuntreated fiber seemed unpleasant because of the nearness of lignin, wax, oil, and surface polluting influences, which are evacuated with alkaline and benzoyl-chloride treatments. By contrasting treated fiber and the untreated strands, it tends to be seen that the alkaline and benzoyl-chloride treatments brought about partition of the small scale fibrillar structure (fibrillation) and decrease in thickness of fiber due to the evacuation of cemented materials.

\section{RESULTS AND DISCUSSIONS}

\subsection{Tensile Properties of Composites}

The effect of chemical treatment on tensile properties of fibercomposites is displayed in Figures 2 and 3. It was observed that due to different chemical treatments of fiber, tensile strength and tensile modulus of the composite increased in both treatments with increase in fiber content, but due to alkaline treatment the composite have more strength and modulus than Benzoylation. The tensile modulusand tensile strengthof the composite increased by $90.56 \%$ and $22.45 \%$ over the raw fiberdue to Alkaline treatment of fiber, $12 \%$ and $58 \%$ increases due to Benzoylaton, respectively.

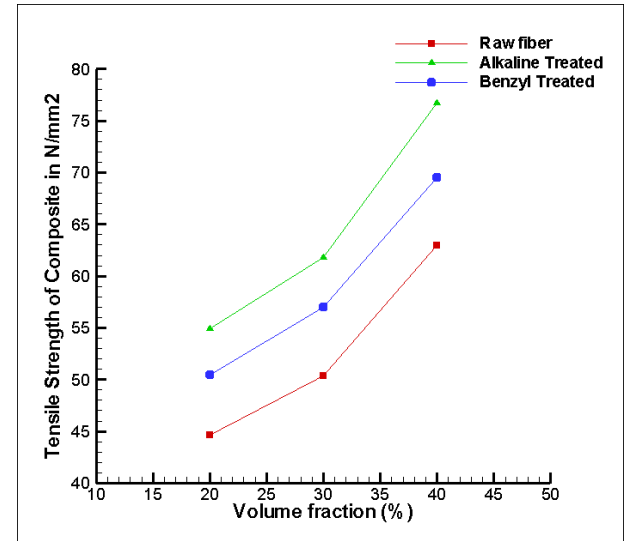

Figure 6(a): Effect of Chemical Treatment on Tensile Strength of Composite

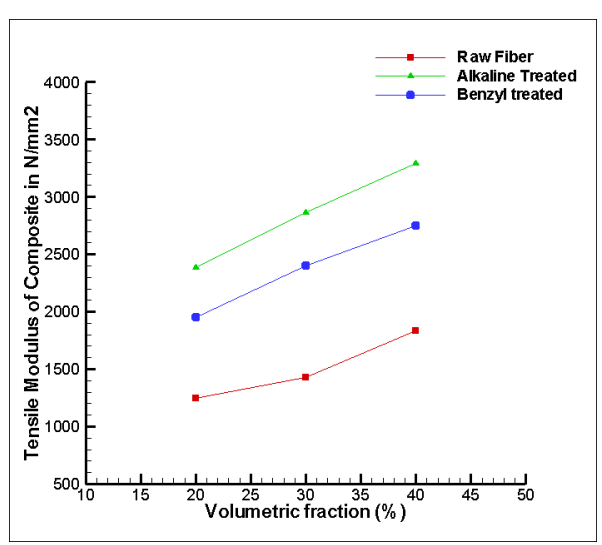

Figure 6(b): Effect of Chemical Treatment on Tensile Modulus of Composite

This is because that the bonding between fiber and matrix is increased due to rough surfaces created on the fiber surface and removing the waste material on the surface of fiber due to both chemical treatments. Finally it is observed that the increase in tensile strength and tensile modulus due to alkaline treatment is more than Benzoylation.

\subsection{Bending strength}

The variation of bending strength of palm fiber-reinforced composite due to chemical treatment of fiber is shown in Figure 4. Figure from above the flexural strength was increased $22.5 \%$ due to alkaline treatment of fiber and $13 \%$ due to benzyl treatment over raw fiber respectively. Increase in bending strength is more owed to alkaline treatment of fiber than benzyl treatment.

\subsection{Impact Strength}

Figure 4 shows the variation in Impact strength of fishtail palm fiber-reinforced composite owing to chemical treatment of fiber. From above figure it is observed that the Impact strength was increased $38.4 \%$ due to alkaline treatment of fiber and $14 \%$ due to benzyl treatment over raw fiber respectively. Increase in Impact strength is more due to alkaline treatment of 
fiber than benzyl treatment.

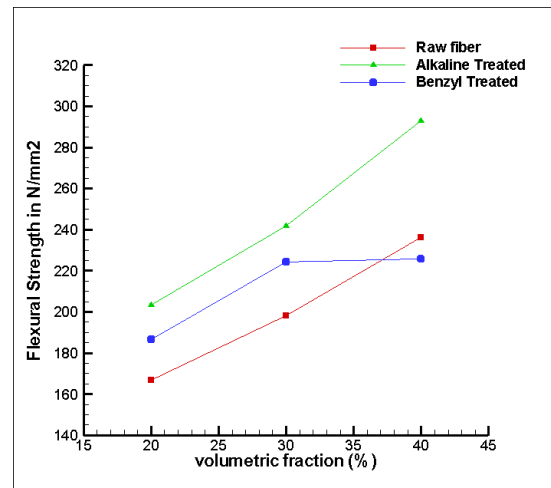

Figure 7: Effect of Chemical Treatment on Flexural Strength of Composite.

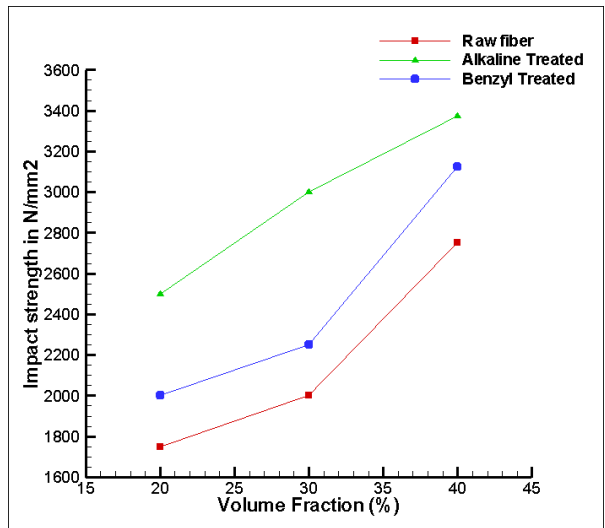

Figure 8: Effect of Chemical Treatment on Strength of Composite

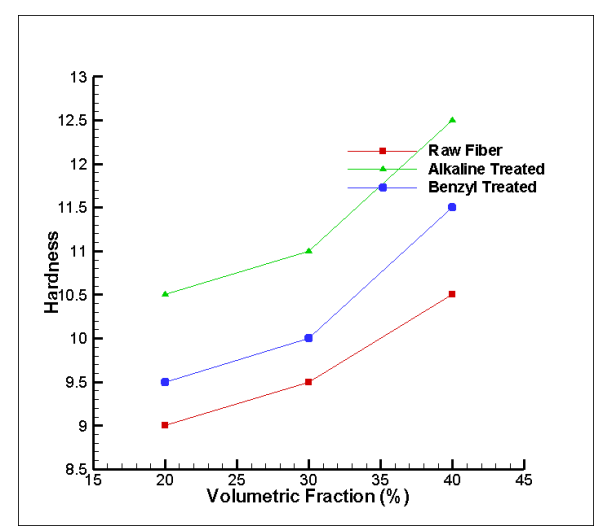

Figure 9: Effect of Chemical Treatment on Impact Hardness of Composite

\subsection{Hardness}

The variation of hardness of palm fiber-reinforced composite due to chemical treatment of fiber is shown in Figure 4 . From above figure it is observed that the hardness was increased $17.15 \%$ due to alkaline treatment of fiber and $7 \%$ due to benzyl treatment over raw fiber respectively. Increase in hardness is more due to alkaline treatment of fiber than benzyl treatment.

\section{MORPHOLOGICAL ANALYSIS}

\subsection{SEM Analysis}

SEM gives an incredible procedure to investigation of morphology of fibers surface and crack surfaces of fiber composites. Morphological changes were analyzed after treatment of fibers. Untreated fiber's SEM micrograph was demonstrates by Fig 2a. These are plainly contained contaminations, wax, greasy matters and rounded bulges called "tyloses" [17]. There were huge contrasts in the fiber morphologies after alkaline and benzyl treatment contrasted with untreated ones. A complete change in the morphological structure of the fibers happened after the alkaline treatment (Fig. 2b). It was seen that the fiber had progressed toward becoming cleaner and the roughness was decreased which practically the sum total of what impurities have been expelling from the fiber surface. 
On the treatment of $\mathrm{NAOH}$ and benzyl, wax and cuticula in the surface were removed by sodium and surface contact becoming smoother. It was discovered that fibrillation occurs as the coupling material is removed and some microspores appear in the fibers being handled. It was also confirmed that the removal of the surface layer could boost the contact region because the fibrils become more vulnerable. It also decreases the fiber diameter and makes the surface rougher. The evacuation of surface debasements on cellulose fibers is favorable for fiber-matrix grip as it offices both mechanical interlocking and the holding response.

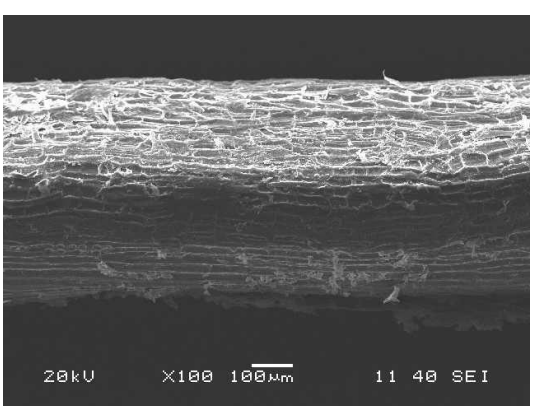

Figure 10(A): SEM Graph for CaryotaUrensUntreated Natural Fber 100X Resolution.

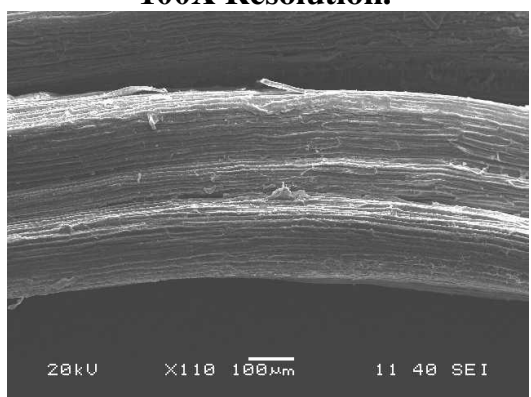

Figure 11(A): SEM Graph for $\mathrm{NaOH}$ Treated CaryotaUrens Natural Fber 100X Resolution.

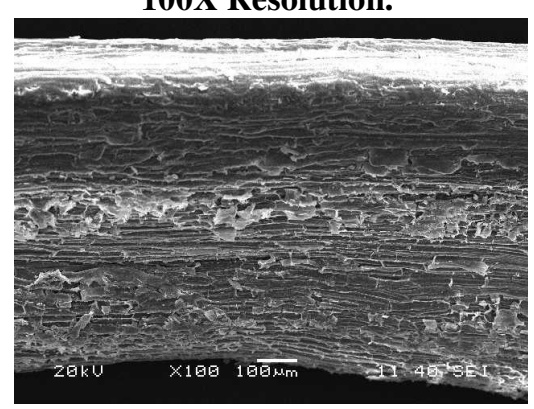

Figure 12(A): SEM Graph for Benzyl Treated CaryotaUrens Natural Fber100X Resolution.

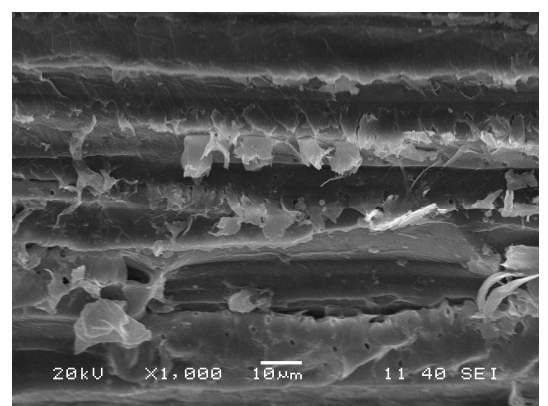

Figure 10(B): SEM Graph for CaryotaUrens Untreated Natural Fber 1000X Resolution.

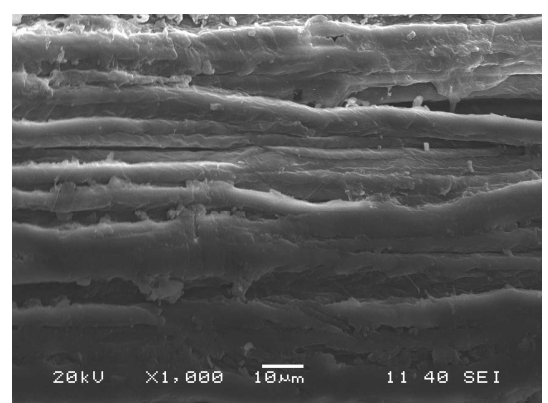

Figure 11(B): SEM Graph For NaOH Treated CaryotaUrens Natural Fber1000X

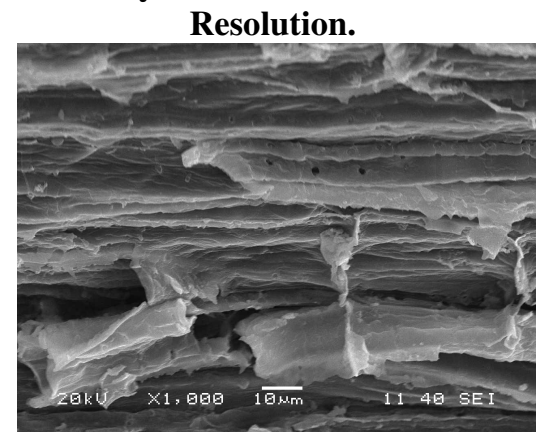

Figure 12(B): SEM Graph for Benzyl Treated CaryotaUrens Natural Fiber 1000X Resolution.

\section{CONCLUSONS}

- It was noticed that Chemical modification of cellulosefibers is necessary for the improvement of mechanical properties of natural fiber (caryotaurens) reinforced composite by increasing the adhesion between the hydrophilic nature of fibers and hydrophobic nature of matrix.

- It was clearly observed that the tensile strength and the flexural strength of the caryotaurensfiber reinforced 
polymer composite were increased by both alkaline treatment and the benzyl chloride treatment. By the observation, $5 \%$ alkaline treatment improves tensile and flexural strength more when compared to benzyl chloride treatment

- The composite tensile modulus with alkaline treated fibers improves nearly double the value of the composite made by raw fibers. So the composite with chemically treated fibershave more stiffness.

- The loss in weight of the fabers after the alkali treatment was observed, due to heavy dissolution of the hemicellulose content.

- Scanning electron microscopy analysis of fiber surfaces illustrates that due to chemical treatment the impurities like wax and fatty substances were removed and roughness on fiber surface was decreased. Due to this the adhesion between fiber and matrix will improve.

- The impact strength and hardness are also improved for composite with chemically treated fibers when compared with composite with raw fiber.

\section{REFERENCES}

1. JericoBiagiotti.,Debora Pugila. Luigi Torre, And Jose MKenny., A systematic investigation on theInfluenceof the chemical treatment of natural fibres on the properties of their polymer matrix composites,J. Poly. Comp,vol. 25(5), 2004, pp. 470479.

2. Sathishkumar, T. P., P. Navaneethakrishnan, and S. Shankar., Tensile and flexural properties of snake grass natural fiber reinforced isophthallic polyester composites, Compos, Sci. Technol,vol. 72, 2012, pp. 1183-1190.

3. Z.Beluouadah, M.Rakbi., Characterizationof new natural cellulosic fibrefrom LygeumSpartum, Carbohydrate Polymers, vol. 134, 2015, pp. 429-437.

4. SatyanarayanaKestur G, H.S. Thais, Flores-Sahagun, Lucas Pereira Das Santos, Juliana Dos Santos, IrinueMazzaro, AlexanderMikowski., Characterization of blue agave bagasse fibres of Mexico, vol. 45, 2013, $\quad$ pp. 153-161.

5. ZofijaJankauskiene, BronislevaButkute, ElvyraGruzdeviene, JurgitiCeseviciene., Chemical composition and physical properties of dew- and water-retted hemp fibres,Ind crops and products, vol. 75(B), 2015. Pp. 206-211.

6. XueLi.LopeG.Tabil.SathayanarayanPhanigarhi., Chemical Treatments of Natural Fibre for Use in Natural Fibre-Reinforced Composites, vol. 15, 2017, pp. 25-33.

7. Leonard Y. Mwaikambo. Martin P.Ansell., Chemical Modification of Hemp, Sisal, Jute, and Kapok Fibres by Alkalization,.J. App. Poly scie,vol. 84, 2002, pp. 2222-2234.

8. M.M. Kabir, H. Wang, K.T. Lau, F.Cardona., Chemical Treatments on Plant-based Natural Fibre Reinforced Polymer Composites, Comp. partB.Engg, vol. 43(7), 2012, pp. 2883-2892.

9. Haigler, C. H., 1985, T. P. Nevell and S. H. Zeronian., The Functions and Biogenesis of Native Cellulose, Cellulose Chemistry and Its Applications, vol. 30, 1985, pp. 83.

10. Morvan, C., Jauneau, A., Flaman, A., Millet, J. andDemarty., Degradation of flax polysaccharides with purified endopolygalacturonase, Carbohydrate Polymers,vol. 13(2), 1990, pp. 149-163.

11. Thygesen, A., Comparison of composites made from fungal de-fibrated hemp with composites of traditional hemp yarn, Industrial Crops and Products,vol. 147, 1981, pp. 195-197. 
12. NirjhariniSamal., Fabrication and Characterization of Acetone Treated Natural FibreReinforced.Polymer Composites 1981, pp. 195--197

13. S. Mishra, A.K. Mohanty, L.T. Drzalb, M. Misrab, S. Parijac, S.K. Nayak,S.S.Tripathy., Studies on Mechanical Performance OfBiofibre/Glass Reinforced Polyester Hybrid Composites, compo.Scie.and ～tech, vol. 63(10), 2003, pp. 1377-1385.

14. A. Valadez-Gonzalez, J.M. Cervantes-Uc, R. Olayo,P.J. Herrera-Franco., Effect of fibersurface treatment on the fiber-matrix bond strength of natural fiber reinforced composites, Comp. part B. Engg, vol. 30,1999, pp. 309-320

15. Murali Mohan Rao, K., A. V. Ratna Prasad, M. N. V. RangaBabu, K. Mohan Rao, and A. V. S. S. K. S. Gupta.,Tensile properties of elephant grass fiber reinforced polyester composites. Mater. Sci, vol. 42, 2007, pp. 3266-3272.

16. Ratna Prasad, A. V., and K. Mohan Rao., Mechanical properties of natural fiber reinforced polyester composites Jowar, sisal, and bamboo, Mater. Des, vol. 32, 2011, pp. 508-513.

17. Ramanaiah, K., A. V. Ratna Prasad, and K. Hema Chandra Reddy., Mechanical properties and thermal conductivity of Typhaangustifolia natural fiber-reinforced polyester composites, Int. J. Polym. Anal. Charact, vol 16,2011, pp. $496-503$.

18. Sathishkumar, T. P., P. Navaneethakrishnan, and S. Shankar., Tensile and flexural properties of snake grassnaturalfiber reinforced isophthallic polyester composites, Compos. Sci. Technol, vol. 72,2012,pp. 1183-1190.

19. Murali Mohan Rao, K., and K. Mohan Rao.. Extraction and tensile properties of natural fibers: Vakka, date and bamboo, Compos. Struct, vol. 77, 2007, pp. 288-295.

20. Rout J, Tripathy SS,Nayak SK, Misra M, Mohanty AK..,Scanning electron microscopystudy of chemically modified coir fibers, J ApplPolymSci,vol. 79(7), 2000, pp. 1169-1177.

21. K. Ramanaiah, A.V. Ratna Prasad \& K. Hema Chandra Reddy.,Mechanical \& Thermo-Physical Properties of Fish Tail Palm Tree Natural Fibre- Reinforced Polyester Composites,Journal of polymer analysis and characterization, vol. 18(2), 2013, pp. 126-136.

22. Mohanty, A.K., Misra, M. and Drzal, L.T., Surface modifications of natural fibers and performance of the resulting biocomposites: An overview, Compos Interfaces, vol. 8, 2001, pp. 313-343. 